\title{
Bacteriological Profile of Urinary Tract Infection at a Tertiary Care Hospital in Kalaburagi, India
}

\author{
Praveen Kumar Doddamani, M. Ravish Kumar* and Prashant Parandekar \\ Department of Microbiology, ESIC medical college, Gulbarga, 585106, India \\ *Corresponding author
}

\section{Keywords \\ Urinary tract infection, Escherichia coli, Antibiotic resistance, Uro- pathogens \\ Article Info \\ Accepted: \\ 12 March 2019 \\ Available Online: \\ 10 April 2019}

A B S T R A C T

Urinary tract infections (UTI) are the second most common infections encountered in clinical practice and is associated with a high rate of morbidity and economic burden. Knowledge of the local antibiotic resistance patterns will help in providing empirical therapy and helps in prevention of resistance. This was a retrospective study conducted from January 2017 to December 2018 at a medical college in South India. Samples received included mid-stream clean catch urine, Catheterized urine, suprapubic aspirate. Urine specimen was collected in a sterile, wide mouth, leak proof, labelled container. Urine was processed immediately within one hour without delay. Samples were processed and isolates were identified as per standard methods. Antibiotic sensitivity testing was done on Mueller Hinton agar by Kirby-Bauer disc diffusion method and CLSI guidelines. Most UTI cases were seen in females and in the age group of 31-40 years. The most common organism isolated was E. coli $(64.4 \%)$, followed by Klebsiella species $(9.9 \%)$ and Pseudomonas aeruginosa (7.4\%). The most common Gram-positive organism was Staphylococcus aureus (5.9\%). Highest resistance was seen with Ampicillin (98\%) and Amoxicillin-clavulanic acid (74\%) and least resistance was seen with Imipenem and Piperacillin-Tazobactam. The inappropriate and irrational empirical use of antibiotics (particularly wide spectrum antibiotics), immuno-suppression, prolonged stay (catherization) are some of the major reasons responsible for resistant urinary tract infections. The present study revealed that urinary tract infections caused by E. coli was resistant to commonly used antibiotics. On the basis of local antibiotic susceptibility pattern, Nitrofurantoin (oral) and Amikacin (parenteral) can be used as first line empiric therapy for treatment of UTI. A major intervention in preventing resistant UTI is the regular monitoring of antibiotic resistance pattern which helps in initiating empirical treatment of UTI and definitive therapy must be initiated only after culture sensitivity report. As the antibiotic resistance pattern changes over a period of time, regular antibiotic susceptibility pattern studies should be conducted region wise.

\section{Introduction}

Urinary tract infections (UTI) are the second most common infections encountered in clinical practice and is associated with a high rate of morbidity and economic burden $(1,2)$. UTI is caused predominantly by Gram negative bacteria such as Escherichia coli (E. coli), Enterobacter species, Klebsiella species and Proteus species. The most common 
organism causing community acquired acute UTI is E. coli (3) and often leading to secondary health issues which can be serious at times (4). UTI may involve only the lower urinary tract or may involve both the upper and lower tract. Malnutrition, low socioeconomic status, poor hygiene is the most important factors associated with UTI (5).

Despite the availability of higher antibiotics, UTI continues to be the most common cause of infections in hospitalized patients, accounting for approximately $40 \%$ of the hospital acquired infections (6). UTIs in hospital and community setting are initially treated empirically based on local antibiotic resistance rates and severity of illness. Organisms causing UTI have shown an increase in resistance to commonly used antibiotics. Fluoroquinolones are extensively used for empirical therapy, because of high bactericidal and clinical cure rates as well as low rates of resistance (7). But recent studies have reported increased resistance to fluoroquinolones (8-10).

The antibiotic therapy relieves the symptoms of UTI and plays an important role in preventing the development of complications like renal scarring. Knowledge of the local antibiotic resistance patterns will help in providing empirical therapy and helps in prevention of resistance. There are few studies conducted on prevalence and antibiotic susceptibility pattern of pathogens causing UTI in this region, hence the present study was conducted.

\section{Materials and Methods}

\section{Sample collection}

This was a retrospective study conducted from January 2017 to December 2018 at a medical college in South India. Patients of either sex aged between 20-60 years who were suspected of having UTI were included in the study. A detailed history of patient including demographics, socioeconomic status, prior antibiotic use, previous history of UTI, hospitalization etc were recorded in the prescribed proforma. Samples received included mid-stream clean catch urine, Catheterized urine, suprapubic aspirate. Urine sample was collected in a sterile, wide mouth, leak proof, labelled container. Urine was processed immediately within one hour without delay. Samples were processed and isolates were identified as per standard methods (11).

\section{Antibiotic sensitivity testing}

Antibiotic sensitivity testing was done on Mueller Hinton agar by Kirby-Bauer disc diffusion method (12) The following antibiotics were tested as per CLSI guidelines (13), Ampicillin (10 mcg), Amoxicillinclavulanic acid (30 mcg), Ceftriaxone (30 mcg), Cefuroxime (30 mcg), Ceftazidime (30 $\mu \mathrm{g})$, Ciprofloxacin $(5 \mathrm{mcg})$, Norfloxacin (10 $\mathrm{mcg}$ ), Amikacin (30 mcg), Gentamicin (10 mcg), Co-trimoxazole $(1.25 / 23.75 \mu \mathrm{g})$ Imipenem (10 mcg), Nitrofurantoin (300 $\mathrm{mcg})$, and Piperacillin-Tazobactam (100/10 $\mathrm{mcg}$ ).

\section{Statistical analysis}

All data were tabulated and analyzed. Descriptive statistics were used for analysis. The data was analyzed using Microsoft excel (2016 version) and the results are explained in frequency and percentage.

\section{Results and Discussion}

During the study period a total of 1568 samples were processed from suspected UTI patients, out of which 525 (33\%) of samples were culture positive with significant growth, $15 \%$ insignificant growth and about $8 \%$ of culture showed contamination. The demographic variables are shown in table 1. 
Most UTI cases were seen in females and in the age group of 31-40 years. The organisms isolated from urine samples are shown in table 2 .

The most common organism isolated was $E$. coli $(64.1 \%)$, followed by Klebsiella species (9.9\%) and Pseudomonas aeruginosa (7.4\%). The most common Gram-positive organism was Staphylococcus aureus (5.9\%). E. coli was commonly isolated from females and in the age group of 31-40 years.

The antibiotic susceptibility pattern of E. coli is shown in table 3. Highest resistance was seen with Ampicillin (98\%) and Amoxicillinclavulanic acid (74\%) and least resistance was seen with Imipenem and PiperacillinTazobactam.
UTI are the one of the most common infections encountered in clinical practice. UTI caused by E. coli has increased over the years, one of the major reasons being irrational use of antibiotics. The distribution of species causing UTI and their antimicrobial pattern varies with time and place (14). In the present study, culture positive rate was $33 \%$, most UTI cases were seen in females and in the age group of 31-40 years. The most common organism isolated was E. coli (64.4\%), followed by Klebsiella species (9.9\%) and Pseudomonas aeruginosa (7.4\%). The most common Gram-positive organism was Staphylococcus aureus (5.9\%). E. coli was commonly isolated from females and in the age group of 31-40 years. Other studies have also reported similar findings $(8,15,16)$.

Table.1 Demographic characteristics of the participants

\begin{tabular}{|lcc|}
\hline Variable & Number & Percentage \\
\hline Gender & 169 & 32.2 \\
Male & 356 & 67.8 \\
Female & & \\
Age group & 119 & 22.6 \\
20-30 years & 176 & 33.5 \\
31-40 years & 104 & 19.8 \\
41-50 years & 126 & 24 \\
$51-60$ years & & \\
\hline
\end{tabular}

Table.2 Organisms isolated from urine samples

\begin{tabular}{|lcc|}
\hline Organism & Number & Percentage \\
\hline E. coli & 337 & 64.1 \\
Klebsiella species & 52 & 9.9 \\
Pseudomonas aeruginosa & 39 & 7.4 \\
Proteus species & 29 & 5.5 \\
Enterococcus species & 29 & 5.5 \\
Staphylococcus aureus & 31 & 5.9 \\
Others & 08 & 1.5 \\
\hline
\end{tabular}


Table.3 Antibiotic susceptibility pattern of $E$. coli $(\mathrm{n}=525)$

\begin{tabular}{|lcc|}
\hline Antibiotic & Sensitive $(\%)$ & Resistant $(\%)$ \\
\hline Ampicillin & $6(1.2)$ & $519(98)$ \\
Amoxicillin-clavulanic acid & $133(25.4)$ & $392(74.6)$ \\
Ceftriaxone & $228(43.4)$ & $297(56.6)$ \\
Cefuroxime & $216(41.2)$ & $309(58.8)$ \\
Ceftazidime & $240(45.7)$ & $285(54.3)$ \\
Ciprofloxacin & $247(47.1)$ & $278(52.9)$ \\
Norfloxacin & $286(54.5)$ & $239(45.5)$ \\
Amikacin & $433(82.5)$ & $92(17.5)$ \\
Gentamicin & $216(41.2)$ & $309(58.8)$ \\
Co-trimoxazole & $188(35.9)$ & $337(64.1)$ \\
Imipenem & $499(95.1)$ & $26(4.9)$ \\
Nitrofurantoin & $391(74.4)$ & $134(25.6)$ \\
Piperacillin-Tazobactam & $480(91.4)$ & $45(8.6)$ \\
\hline
\end{tabular}

The antibiotic susceptibility pattern of $E$. coli is shown in table 3. Highest resistance was seen with Ampicillin (98\%) and Amoxicillinclavulanic acid (74\%) and least resistance was seen with Imipenem (4.9\%) and PiperacillinTazobactam (8.6\%). Significant resistance was also seen with fluoroquinolone and cephalosporin group of antibiotics $(2,5,17)$. The reason for the development of resistance to commonly used antibiotics might be irrational therapeutic and undue prophylactic use, easy availability (over the counter sale) of the antibiotics and inappropriate dosing schedule. Resistance to aminoglycoside group of antibiotics was low with amikacin. Resistance to cotrimoxazole was high (64.1\%), and to nitrofurantoin was $25.6 \%$. Other studies have reported low resistance to nitrofurantoin ranging from $1 \%$ to $13 \%$ (1819). This variation might be due to different geographical, patient and hospital characteristics. Least resistance was seen with Imipenem and Piperacillin-Tazobactam. Other studies have also reported similar findings (17-20). The inappropriate and irrational empirical use of antibiotics (particularly wide spectrum antibiotics), immuno-suppression, prolonged stay (catheterization) and lack of appropriated laboratory services are some of the major reasons responsible for resistant urinary tract infection.

\section{Limitations of the study}

The present study was conducted at a single center and the samples size was small, so results cannot be generalized. Future studies should include regional hospitals with large sample size.

In conclusion, the present study revealed that urinary tract infections caused by E. coli was resistant to commonly used antibiotics. On the basis of local antibiotic susceptibility pattern, Nitrofurantoin (oral) and Amikacin (parenteral) can be used as first line empiric therapy for treatment of UTI. A major intervention in preventing resistant UTI is the regular monitoring of antibiotic resistance pattern which helps in initiating empirical treatment of UTI and definitive therapy must be initiated only after culture sensitivity report. As the antibiotic resistance pattern changes over a period of time, regular antibiotic susceptibility pattern studies should be conducted region wise. 


\section{References}

1. Gatermann SG. Bacterial infections of the urinary tract. In: Borriello P, Murray PR, Funke G. editors. Topley \& Wilson's microbiology \& microbial infections, $10^{\text {th }}$ ed. vol. III. London: Hodder Arnold Publishers; 2007:671-83.

2. Pai V, Nair B. Aetiology and sensitivity of uropathogens in outpatients and inpatients with urinary tract infection: Implications on empiric therapy. Ann Trop Med Public Health. 2012; 5:181-84.

3. Sobel JD, Kaye D. Urinary tract infections. In: Mandell GL, Bennett JE, Dolin R, editors. Mandell, Douglas and Bennett's Principles and Practice of Infectious Diseases. 7th ed., Vol. 1. Philadelphia, USA: Churchill Livingstone Elsevier Publication; 2010. p. 958-72.

4. Kalsoom BA, Jafar KH, Begum H, Munir S, ul AKBAR N, Ansari JA, Anees M. Patterns of antibiotic sensitivity of bacterial pathogens among urinary tract infections (UTI) patients in a Pakistani population. African Journal of Microbiology Research 2012; 16; 6:41420.

5. Akram M, Shahid $M$ and Khan AU. Etiology and antibiotic resistance patterns of community acquired urinary tract infections in JNMC Hospital, Aligarh, India. Ann Clin Microbiol Antimicrob. 2007; 6: 6-11.

6. Kamat US, Fereirra A, Amonkar D, Motghare DD, Kulkarni MS. Epidemiology of the hospital acquired urinary tract infections in a medical college hospital in Goa. IJU 2009; 25(1):76.

7. Zervos MJ, Hershberger E, Nicolau DP, Ritchie DJ, Blackner LK, Coyle EA, et al., Relationship between fluoroquinolone use and changes in susceptibility to fluoroquinolones of selected pathogens in United States teaching hospitals, 1991-
2000. Clin Infect Dis 003; 37: 1643-8.

8. Mandal J, Acharya NS, Buddhapriya D, Parija SC. Antibiotic resistance pattern among common bacterial uropathogens with a special reference to ciprofloxacin resistant Escherichia coli. Indian J Med Res., 2012; 136: 842-849.

9. Shariff VAAR, Shenoy MS, Yadav TMR. The antibiotic susceptibility patterns of uropathogenic Escherichia coli, with special reference to the fluoroquinolones. J. Clin Diagn Res 2013; 76):1027-30.

10. Hwang TJ, Hooper DC. Association between fluoroquinolone resistance and resistance to other antibiotic agents among Escherichia coli urinary isolates in the outpatient setting: a national crosssectional study. J Antimicrob Chemother 2014: 69(6):1720-2.

11. Collee JG, Duguid JP, Fraser AG, Marmion BP, Simmons A. Laboratory strategy in the diagnosis of infective syndromes. In: Collee JG, Fraser AG, Marmion BP, Simmons A, editors. Mackie \& McCartney Practical Medical Microbiology, 14th Ed. New York: Churchill Livingstone; 1999: 84-90.

12. Bauer AW, Kirby WM, Sherris JC, Turck M. Antibiotic susceptibility testing by a standardized single disk method. Am J Clin Pathol 1966; 45:493- 6.

13. Wilker M A CFR, Bush K, Dudley M N, et al., The Performance of Standards for Antibiotic Disk Susceptibility Tests: Approved Standard. Clinical and Laboratory Standards Institute. 2009; 29(1): 11-12.

14. Ullah F, Malik SA, Ahmed J. Antibiotic susceptibility pattern and ESBL prevalence in nosocomial Escherichia coli from urinary tract infections in Pakistan. Afr J Biotechnol 2009; 8: 3921- 6.

15. Manjunath G, Prakash R, Vamseedhar Annam KS. The changing trends in the spectrum of the antibiotic drug resistance pattern of the uropathogens which were 
isolated from hospitals and community patients with urinary tract infections in Tumkur and Bangalore. Int $\mathrm{J}$ Biol Med Res. 2011; 2(2):504-07.

16. Pallavi K, Georgi A, Asik MA, Prathiba M, Milly M. Urinary tract infections in the era of newer immunosuppressant agents: A tertiary care center study. Saudi Journal of Kidney Diseases and Transplantation. 2010; 21(5):876-80.

17. Eshwarappa M, Dosegowda R, Aprameya IV, Khan MW, Kumar PS, Kempegowda P. Clinico-microbiological profile of urinary tract infection in South India. Indian J Nephrol 2011; 21:30-6.

18. Abdul Rahaman Shariff V A, Suchitra Shenoy M, Taruna Yadav, Radhakrishna M. The Antibiotic Susceptibility Patterns of Uropathogenic Escherichia coli, With
Special Reference to the Fluoroquinolones. Journal of Clinical and Diagnostic Research. 2013; 7(6):1027-30.

19. Syed Mustaq Ahmed, Ramakrishna Pai Jakribettu, Shaniya Koyakutty, Arya B, Shakir VPA. Urinary Tract Infections An overview on the Prevalence and the Anti-biogram of Gram Negative Uropathogens in A Tertiary Care Centre in North Kerala, India. Journal of Clinical and Diagnostic Research, 2012;6(7):119295.

20. Jayanta Debnath, Pradip KR. Das, Munmun Debnath, K.K. Haldar. Aetiological Profile and Antibiotic Susceptibility Pattern in Patients with Urinary Tract Infection in Tripura. Journal of Clinical and Diagnostic Research. 2014; (8): DL01-DL02

\section{How to cite this article:}

Praveen Kumar Doddamani, M. Ravish Kumar and Prashant parandekar. 2019. Bacteriological Profile of Urinary Tract Infection at a Tertiary Care Hospital in Kalaburagi, India. Int.J.Curr.Microbiol.App.Sci. 8(04): 1538-1543. doi: https://doi.org/10.20546/ijcmas.2019.804.178 